\title{
DEGRADAÇÃO FÍSICA DE UM LATOSSOLO VERMELHO UTILIZADO PARA PRODUÇÃO INTENSIVA DE FORRAGEM(1)
}

\author{
Neyde Fabíola Balarezo Giarola ${ }^{(2)}$, Cássio Antônio Tormena ${ }^{(3)} \&$ \\ Adriano Cassol Dutra ${ }^{(4)}$
}

\begin{abstract}
RESUMO
A degradação e a perda de qualidade do solo podem ocorrer em áreas cultivadas com forragens para produção de feno devido ao freqüente e intenso tráfego de máquinas. Neste trabalho foi testada a hipótese de que sistemas de produção intensiva de forragem para fenação podem conduzir à degradação da qualidade física do solo. O objetivo deste estudo foi quantificar atributos físicos e morfológicos do solo para reconhecer e identificar a degradação física de um Latossolo Vermelho cultivado com a forrageira Tifton 85 (Cynodon spp.) para produção de feno, na região oeste do Paraná, Sul do Brasil. Utilizou-se uma área sob floresta nativa, contígua à área experimental, como referência de qualidade física do solo. Realizaram-se avaliações morfológicas dos perfis de solo e, nos horizontes A e Bw, foram determinadas as seguintes propriedades físicas do solo: densidade do solo, porosidade total e distribuição de poros e a curva de resistência do solo à penetração. As alterações ocorridas nos atributos morfológicos e físicos comprovaram a degradação física do solo cultivado com forrageira para produção de feno e confirmam a hipótese do trabalho. No solo cultivado com forrageira, verificaramse reduções da macroporosidade e da porosidade total, bem como aumentos da densidade do solo e da resistência do solo à penetração. Sob uso intensivo para produção de forrageira, a camada superficial do solo apresentou porosidade com ar menor do que $10 \%$ e resistência deste à penetração superior a 2,5 MPa. Os atributos morfológicos apenas permitiram localizar as alterações físicas ocorridas no solo, enquanto as propriedades físicas avaliadas possibilitaram quantificar a
\end{abstract}

\footnotetext{
(1) Recebido para publicação em novembro de 2005 e aprovado em junho de 2007.

(2) Professora do Departamento de Ciência do Solo e Engenharia Agrícola, Universidade Estadual de Ponta Grossa - UEPG. Av. Gal. Carlos Cavalcanti 4748, Uvaranas, CEP 84030-900 Ponta Grossa (PR). E-mail: neydef@uepg.br

${ }^{(3)}$ Professor do Departamento de Agronomia, Universidade Estadual de Maringá - UEM. Av. Colombo 5790, CEP $87020-900$ Maringá (PR). Bolsista do CNPq. E-mail: catormena@uem.br

(4) Engenheiro-Agrônomo, C-Vale. Av. Idemar Riedi 11040, CEP 78890-000 Sorriso (MT). E-mail: adriano.dutra@cvale.com.br
} 
ocorrência da degradação física do solo. A curva de resistência do solo refletiu sensivelmente a degradação estrutural da camada superficial do solo cultivado com forrageira para produção de feno.

Termos de indexação: compactação do solo, macroporosidade, resistência do solo à penetração, densidade do solo, degradação do solo.

\section{SUMMARY: PHYSICAL DEGRADATION OF A RED LATOSOL USED FOR INTENSIVE FORAGE PRODUCTION}

The intensive traffic of agricultural machines on soils used for hay production can result in soil quality degradation. The hypothesis evaluated was that systems of intensive hay production cause soil physical degradation. The objective of this study was to quantify the soil physical properties and morphological attributes to recognize and identify the soil physical degradation of a Red Latosol (Typic Haplorthox) cropped with Tifton 85 forage (Cynodon spp) for hay production, in western Paraná state, southern Brazil. A native forest area adjacent the experimental area was used as reference for soil physical quality. Morphological attributes were described in both soils and, in the $A$ and BW horizons, the following soil physical properties were measured: bulk density, porosity and pore size distribution, and soil resistance to penetration (SRP). The analysis of these variables confirmed the hypothesis. Soil morphological description showed the occurrence of soil compaction as well as drastic alterations in macromorphological characteristics at a depth of $0.15 \mathrm{~m}$ in the soil under forage cultivation for hay production. Reductions in soil total porosity and macroporosity were verified as well as increases in soil bulk density and SRP. Under intensive forage production the air-filled porosity in the soil surface layer was found to be lower than $10 \%$ and SRP over 2.5 MPa. The morphological attributes only allowed identifying where soil physical modifications occurred, while the soil physical properties indicated the degree of the soil physical degradation. The SRP curve clearly demonstrated the soil physical degradation in the surface layer of the soil used for cultivated with forage for hay production.

Index terms: soil compaction, macroporosity, soil resistance to root penetration, bulk density, soil degradation.

\section{INTRODUÇÃO}

Nos países em desenvolvimento, as necessidades atuais de forragem para produção pecuária excedem a produção sustentável das pastagens e dos solos que as suportam. Sistemas intensivos de exploração agropecuária exigem a utilização de forrageiras com elevada produtividade e qualidade de biomassa, cujo processo de produção e conservação utiliza intensivamente máquinas e equipamentos. Nesses sistemas de produção, acentuam-se os riscos de degradação física dos solos, com reflexos negativos em termos agronômicos e ambientais, cuja magnitude depende das características dos solos, das condições climáticas e do manejo utilizado.

A compactação é um dos principais processos de degradação física dos solos em sistemas agropecuários que utilizam a fenação como estratégia para produção e conservação de forragens. A compactação resulta da perda da estabilidade estrutural devido ao declínio da matéria orgânica associada ao intenso e freqüente tráfego de máquinas no solo, quando o elevado teor de água do solo estabelece a redução na sua capacidade de suporte de carga (Douglas, 1994). Um incremento na compactação do solo resulta em maior densidade deste (Azenegashe et al., 1997), diminuição da porosidade total e alteração na distribuição de diâmetro dos poros e nas suas propriedades hidráulicas (Dexter, 1988). Outros efeitos podem ser verificados em aspectos morfológicos da estrutura do solo via modificações na forma, aspecto e tamanho dos agregados (Warren et al., 1986), bem como em aumento no impedimento mecânico ao crescimento radicular das plantas (Willatt \& Pular, 1983; Bennie, 1991).

A fertilidade do solo tem sido o principal fator levado em conta para obtenção de elevadas produtividades das forrageiras. No entanto, a compactação dos solos cria um ambiente físico desfavorável ao crescimento das plantas e pode impor severas restrições à produtividade e longevidade das forrageiras, mesmo em condições ideais de fertilidade (Silva et al., 1997; Imhoff et al., 2000). A idéia de que apenas os atributos químicos dos solos limitam a produtividade das 
pastagens perenes ainda persiste (Gijsman \& Thomas, 1996), porque é difícil estabelecer relações entre a produtividade das culturas e os atributos físicos e morfológicos do solo. Essa dificuldade decorre, entre outros fatores, da elevada variabilidade espacial e temporal desses atributos no perfil do solo (Letey, 1985).

A ocorrência de deformações estruturais e da compactação do solo pode ser qualitativamente comprovada em pequenas trincheiras, nas quais se procede à observação e identificação de atributos morfológicos dos solos (Tavares Filho, 1999; Ralisch et al., 2001). A análise do perfil fornece uma visão da ação dos implementos nas mudanças na estrutura do solo, indicando as modificações estruturais resultantes das ações de manejo (Manichon, 1995). Quantitativamente, os processos mencionados podem ser diagnosticados, medindo diferentes atributos físicos ligados à condição estrutural do solo. A quantificação desses atributos reduz o grau de subjetividade no que se refere à interpretação dos efeitos do manejo sobre a qualidade física e estrutural do solo para o crescimento das plantas, muito embora demande tempo, material e conhecimento técnico especializado para sua obtenção.

Na região oeste do Paraná, o cultivo da forrageira Tifton 85 (Cynodon spp.) para altas produtividades de feno (quatro a oito cortes por ano) é realizado, geralmente, em solos de textura muito argilosa, em que são feitas aplicações de doses elevadas de fertilizantes químicos e orgânicos (estes oriundos da produção de aves e suínos). Assouline et al. (1997) indicaram a elevada suscetibilidade à compactação dos solos dessa região, principalmente daqueles com caráter eutrófico, que são mais utilizados para produção intensiva de forrageiras. Nesses solos são realizadas, normalmente, cinco passadas de máquinas por corte, sem controle da umidade do solo, por ocasião do tráfego das máquinas. Mesmo adotando estratégias de correção e adubação dos solos, constatam-se baixos índices de produtividade e perda da qualidade do feno produzido em diversas áreas de sua produção. Essa situação coincide com a verificada em pesquisas que comprovam a influência negativa da perda da qualidade física do solo na qualidade e produtividade das forrageiras, a exemplo de Douglas (1994). No entanto, até o presente momento, não são adotadas estratégias de prevenção e de controle dos problemas físicos devido à falta de informações que indiquem, nesses sistemas de produção, que a deterioração dos atributos físicos possa estar limitando a produtividade das forrageiras.

Neste trabalho, estabeleceu-se a hipótese de que o sistema de produção de feno realizado nas condições de manejo, dos solos e de clima da região oeste do Paraná concorre para a degradação e perda da qualidade física e estrutural do solo. O objetivo foi avaliar, por meio de atributos morfológicos e físicos, as alterações ocorridas em um Latossolo Vermelho decorrentes da sua utilização para produção de feno, tendo como referência um solo sob floresta nativa.

\section{MATERIAL E MÉTODOS}

O estudo foi realizado no município de Marechal Cândido Rondon, região oeste do Paraná, em área de ocorrência de Latossolo Vermelho distroférrico muito argiloso, produto da alteração de basalto da Formação Serra Geral (Embrapa, 1984). O clima da região é do tipo Cfa, com temperaturas médias anuais entre 17 e $19^{\circ} \mathrm{C}$, chuvas entre 1.200 e $2.000 \mathrm{~mm}$, relativamente bem distribuídas durante o ano, sendo dezembro, janeiro e fevereiro e junho, julho e agosto os meses mais e menos chuvosos, respectivamente (Iapar, 2000).

Foram selecionadas duas áreas contíguas para este estudo: uma sob floresta nativa preservada e outra, utilizada há sete anos para produção de feno com a forrageira Tifton 85 (Cynodon spp.). Antes do cultivo da forrageira, a área era utilizada para plantio de culturas anuais no sistema convencional de preparo de solo. Para introdução da forrageira, o solo foi descompactado com escarificador de cinco hastes e nivelado com grade leve. O sistema de produção adotado segue o padrão regional de produção, sendo realizadas adubações químicas com fertilizantes minerais (NPK), segundo as recomendações técnicas para a cultura da forrageira Tifton 85 (Malavolta et al., 1986). Associadas às adubações minerais, foram realizadas aplicações eventuais de cama de aviário e dejetos líquidos de suíno, em doses variáveis, conforme a disponibilidade desses produtos e quando verificados sintomas de amarelecimento das plantas e, ou, redução do volume de produção de feno. As fertilizações não estavam mantendo a longevidade e produtividade da forrageira, sendo verificados redução na população de plantas e sintomas de deficiência de nutrientes, em especial do $\mathrm{N}$.

A avaliação morfológica dos solos foi feita em trincheiras de 2,00 $\mathrm{m}$ de profundidade por 1,80 $\mathrm{m}$ de largura e comprimento. A descrição morfológica detalhada dos horizontes estudados foi realizada conforme Lemos \& Santos (2002), a qual permitiu identificar os horizontes e realizar a classificação taxonômica do solo, além de localizar as camadas compactadas por meio da avaliação de mudanças estruturais, pelas diferenças na consistência dos horizontes do perfil e pelas alterações na porosidade e na atividade biológica resultantes do manejo efetuado na área.

As propriedades físicas do solo foram determinadas em amostras indeformadas, coletadas na parede de trincheiras. Foram abertas duas trincheiras, uma sob floresta e outra sob forrageira perene, pois os perfis selecionados eram modais da região e situavam-se em relevo plano (1\% de declividade). Nas faces de cada trincheira, especificamente nos horizontes A e Bw, foram coletadas amostras indeformadas em anéis cilíndricos de aço inox com capacidade de $50 \mathrm{~cm}^{3}$, sendo coletadas 24 amostras no horizonte A e 24 no horizonte $\mathrm{Bw}$, perfazendo um total de 48 amostras por perfil de 
solo, totalizando 96 anéis coletados. Em seguida, as amostras foram envoltas em papel-alumínio, acondicionadas em sacos plásticos e mantidas sob temperatura de aproximadamente $5{ }^{\circ} \mathrm{C}$ até serem processadas. Nessas amostras determinaram-se a curva de resistência do solo à penetração, a densidade do solo e a porosidade do solo distribuída em diferentes classes de tamanho de poros. Nos mesmos horizontes, foram retiradas amostras deformadas (cerca de $300 \mathrm{~g}$ ), para determinação da distribuição de tamanho de partículas e para as análises químicas para fins de fertilidade do solo (Embrapa, 1997). A caracterização dos atributos químicos e da granulometria dos perfis estudados é apresentada nos quadros 1 e 2, respectivamente.
As amostras indeformadas, após devidamente preparadas, foram saturadas por meio da elevação gradual de uma lâmina de água numa bandeja, até atingir cerca de dois terços da altura do anel, durante 48 h. Em seguida, para obter ampla variação de resistência à penetração entre as amostras, estabeleceu-se um gradiente de umidade entre as amostras por meio da aplicação de diferentes potenciais mátricos ( $\psi)$ em mesa de tensão e em câmaras de pressão, conforme Klute (1986). Foram utilizadas três amostras por potencial, sendo aplicados os seguintes potenciais

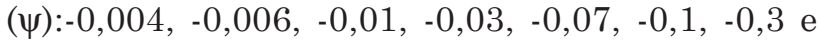
$-1,5 \mathrm{MPa}$. Em seguida, foi determinada a resistência do solo à penetração, utilizando o procedimento e o equipamento descritos por Tormena et al. (1998b).

Quadro 1. Atributos químicos do Latossolo Vermelho sob floresta nativa e forrageira

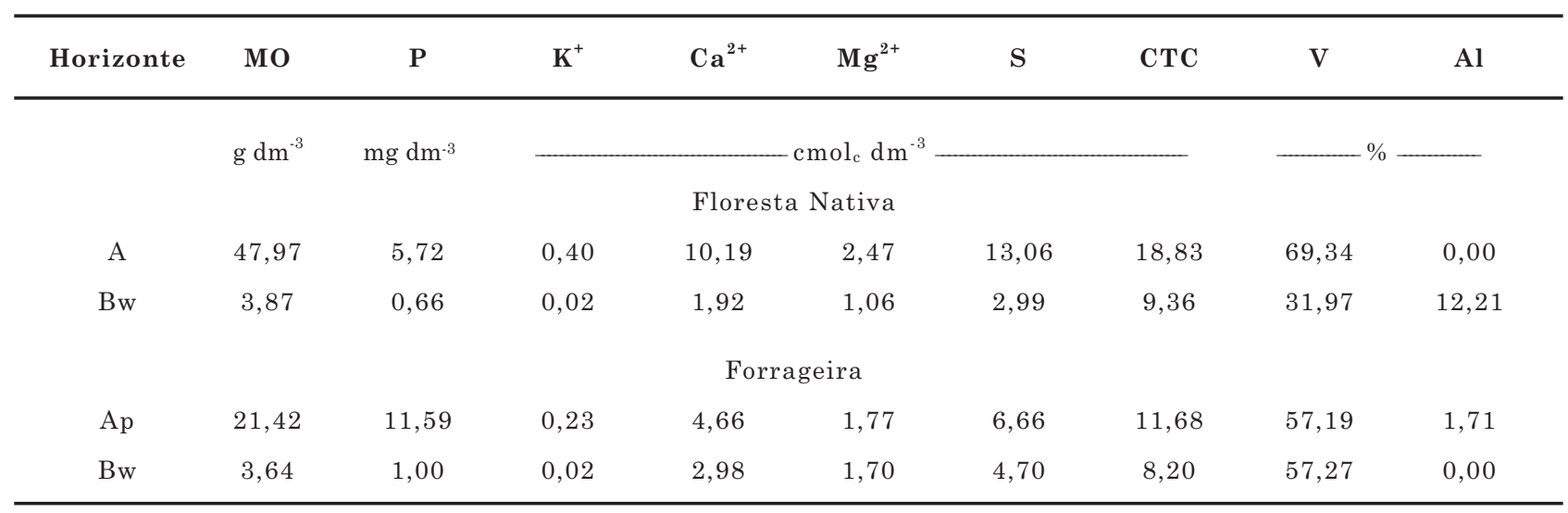

Quadro 2. Composição granulométrica e profundidade dos horizontes do Latossolo Vermelho sob floresta nativa e forrageira

\begin{tabular}{|c|c|c|c|c|c|}
\hline \multirow{2}{*}{ Horizonte } & \multicolumn{5}{|c|}{ Granulometria } \\
\hline & Profundidade & Areia & Silte & Argila & Silte/argila \\
\hline & $\mathrm{m}$ & $\underline{-}$ & $\mathrm{kg}^{-1}$ & $\underline{-}$ & \\
\hline & \multicolumn{5}{|c|}{ Perfil sob floresta nativa } \\
\hline $\mathrm{A}$ & $0,00-0,18$ & 40 & 70 & 890 & 0,08 \\
\hline $\mathrm{AB}$ & $0,18-0,42$ & 30 & 120 & 850 & 0,14 \\
\hline $\mathrm{BA}$ & $0,42-0,71$ & 30 & 90 & 880 & 0,10 \\
\hline \multirow[t]{2}{*}{$\mathrm{Bw}$} & $0,71+$ & 30 & 70 & 900 & 0,08 \\
\hline & \multicolumn{5}{|c|}{ Perfil sob forrageira } \\
\hline Ap & $0,00-0,08$ & 30 & 130 & 840 & 0,15 \\
\hline $\mathrm{AB}$ & $0,08-0,33$ & 30 & 120 & 850 & 0,14 \\
\hline $\mathrm{BA}$ & $0,33-0,68$ & 30 & 100 & 870 & 0,11 \\
\hline $\mathrm{Bw}$ & $0,68+$ & 30 & 80 & 890 & 0,09 \\
\hline
\end{tabular}


Após esta etapa, as amostras foram secas em estufa a $\pm 105^{\circ} \mathrm{C}$, por $24 \mathrm{~h}$, para determinação do teor de água e da densidade do solo, conforme Blake \& Hartge (1986).

A porosidade total foi calculada como sendo o teor de água do solo saturado. A quantificação dos valores de macroporosidade (poros $\geq 50 \mu \mathrm{m}$ ) e microporosidade (poros $<50 \mu \mathrm{m}$ ) foi obtida submetendo todas as amostras ao potencial de -0,006 MPa (Dexter, 1988), utilizando a mesa de tensão. Macroporos foram estimados como a diferença entre o teor de água do solo saturado e o teor de água do solo após aplicação do potencial de -0,006 MPa. O volume de microporos foi estimado como sendo o teor de água retido no potencial de -0,006 $\mathrm{MPa}$.

A resistência do solo à penetração $(\mathrm{RP})$ é influenciada pelo teor de água no solo $(\theta)$, de forma que uma relação funcional entre $\mathrm{RP}$ e $\theta$ pode ser identificada como curva de resistência do solo à penetração (CRP). A CRP foi ajustada por meio da equação utilizada por Busscher et al. (1997) e descrita na equação 1:

$$
\mathrm{RP}=a \theta^{b}
$$

em que RP é a resistência do solo à penetração (MPa); $\theta$, o teor de água no solo $\left(\mathrm{m}^{3} \mathrm{~m}^{-3}\right)$; e a e $b$, os coeficientes da equação.

A comparação entre os tratamentos das variáveis densidade do solo, porosidade total, macro e microporosidade foi feita utilizando o teste $t$ para amostras independentes, conforme Hatcher \& Stepanski (1997). A avaliação da densidade do solo em que ocorre ótimo ou restritivo crescimento das raízes foi realizada utilizando os critérios e as funções de pedotransferência descritos por Jones (1983). O ajuste da curva de resistência do solo à penetração foi realizado com a rotina PROC NLIN (SAS, 1999).

\section{RESULTADOS E DISCUSSÃO}

As localizações dos horizontes e das camadas, bem como as descrições morfológicas dos perfis de solo sob floresta e sob forrageira, encontram-se na figura 1 e no quadro 3. Nas avaliações morfológicas do solo, verificou-se que o solo sob floresta mostrava as condições naturais típicas de um solo preservado, com presença de uma liteira espessa e sem sinais de escoamento superficial de água. O horizonte $\mathrm{A}$ apresentava-se bastante desenvolvido e cor com baixa relação valor/croma, indicativo da elevada concentração de carbono. No solo sob floresta, o arranjamento das unidades estruturais revelou uma estrutura de grau forte, do tipo grumosa, no horizonte A. Em subsuperfície (horizonte Bw), a estrutura era de grau forte, do tipo granular muito pequena (microagregada), com aspecto maciço poroso, comum aos Latossolos Vermelhos provenientes de basalto, em acordo com as constatações de Kertzman (1996). A porosidade era visível e muito comum, principalmente devido à presença de canais e cavidades resultantes da intensa atividade biológica.

No solo sob forrageira, constataram-se alterações importantes em aspectos morfológicos da estrutura do solo, quando comparado ao solo sob floresta (Quadro 3). O tapete vegetal era descontínuo, com reboleiras de plantas mal desenvolvidas e amareladas e sinais de erosão pelo escoamento superficial de água.

Em comparação com o solo sob floresta, verificouse que, no solo sob a forrageira, o manejo utilizado impôs modificações na morfologia do solo até cerca de $0,40 \mathrm{~m}$ de profundidade. Os primeiros $0,08 \mathrm{~m}$ apresentaram drástica modificação na estrutura, o que pode ser verificado comparando as descrições morfológicas dos dois perfis (Quadro 3). A camada de 0,00-0,15 m (horizonte Ap e o topo de AB) apresentouse composta por pequenos e médios agregados do tipo blocos subangulares e angulares compactos, com face alisada, seguida por uma camada menos compacta (base de $\mathrm{AB}$ ), onde apareceram também grandes agregados com menor grau de definição. Logo após o horizonte $\mathrm{AB}$, constatou-se uma camada menos compactada, que, morfologicamente, se assemelhou e passou a ser descrita como horizonte Bw. A partir de 0,35 m, o perfil do solo sob forrageira apresentou-se, morfologicamente, semelhante ao da mata. Neste solo, (a)

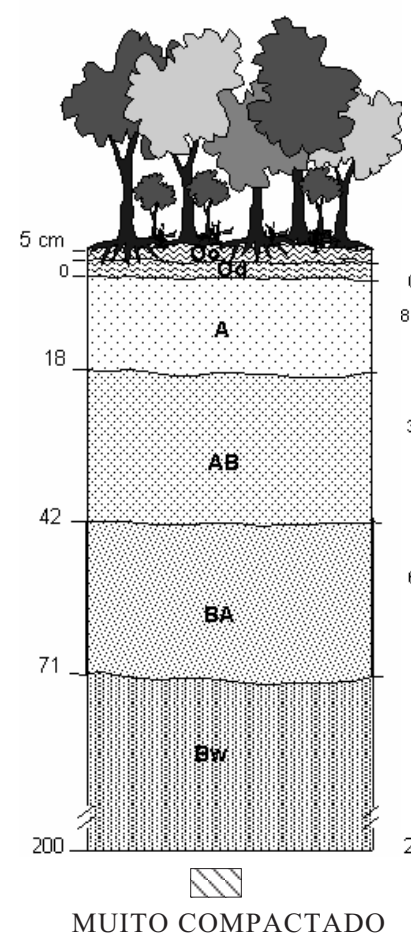

(b)

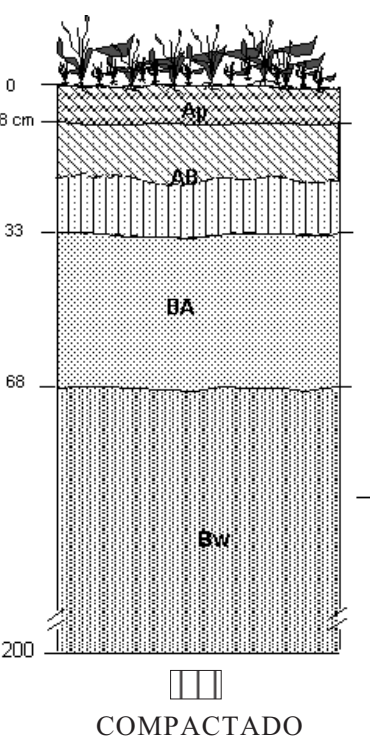

Figura 1. Ilustração esquemática da subdivisão dos horizontes dos perfis do Latossolo Vermelho sob floresta nativa (a) e forrageira (b). 


\section{Quadro 3. Descrição dos perfis de solo da área sob floresta (Perfil 1) e da área sob uso com forrageira (Perfil 2)}

\begin{tabular}{|c|c|c|}
\hline \multicolumn{3}{|r|}{ Perfil 1 - Floresta Nativa } \\
\hline Classificação & - & $\begin{array}{l}\text { Latossolo Vermelho distroférrico típico A chernozêmico textura muito } \\
\text { argilosa fase floresta tropical subperenifólia relevo plano }\end{array}$ \\
\hline Localização & - & Marechal Cândido Rondon (PR) \\
\hline Litologia e formação geológica & - & Basalto, Grupo São Bento, Formação Serra Geral \\
\hline Material de origem & - & Produto de alteração do basalto, Mesozóico - Triássico/Jurássico \\
\hline Relevo & - & Plano \\
\hline Drenagem & - & Acentuadamente drenado \\
\hline Vegetação primária & - & Floresta Estacional Semidecidual \\
\hline Uso atual & - & Floresta preservada \\
\hline \multicolumn{3}{|l|}{ Descrição Morfológica } \\
\hline Oo & - & 0,05-0,03 m - serapilheira - folhas e galhos pouco decompostos \\
\hline Od & - & 0,03-0,00 m - serapilheira - material orgânico bastante alterado. \\
\hline A & - & $\begin{array}{l}\text { 0,00-0,18 m, Vermelho-Escuro-Acinzentado (2,5YR 3/2); muito argilosa; forte } \\
\text { pequena e média grumos; friável a muito friável; transição difusa e plana }\end{array}$ \\
\hline $\mathrm{AB}$ & - & $\begin{array}{l}\text { 0,18-0,42 m, Bruno-Avermelhado-Escuro }(2,5 \mathrm{YR} 3 / 3) \text {; muito argilosa; fraca } \\
\text { pequena e média blocos subangulares e forte pequena e média granular; } \\
\text { friável a muito friável; transição difusa e plana }\end{array}$ \\
\hline BA & - & $\begin{array}{l}0,42-0,71 \mathrm{~m} \text {, Bruno-Avermelhado-Escuro }(2,5 \mathrm{YR} 3,5 / 3) \text {; muito argilosa; } \\
\text { fraca grande e média blocos subangulares que se desfaz em forte pequena e } \\
\text { muito pequena granular; friável a muito friável; transição difusa e plana }\end{array}$ \\
\hline Bw & - & $\begin{array}{l}0,71^{+} \mathrm{m} \text {, Bruno-Avermelhado-Escuro a Vermelho-Escuro }(2,5 \mathrm{YR} 3,5 / 4) \\
\text { muito argilosa; fraca média blocos subangulares que se desfaz em forte } \\
\text { pequena e muito pequena granular; friável a muito friável }\end{array}$ \\
\hline & & Perfil 2 - Forrageira Perene \\
\hline Classificação & - & $\begin{array}{l}\text { Latossolo Vermelho eutroférrico típico A moderado textura muito argilosa } \\
\text { fase floresta tropical subperenifólia relevo plano }\end{array}$ \\
\hline Localização & - & Marechal Cândido Rondon (PR). \\
\hline Litologia e formação geológica & - & Basalto, Grupo São Bento, Formação Serra Geral \\
\hline Material de origem & - & produto de alteração do Basalto, Mesozóico - Triássico/Jurássico \\
\hline Relevo & - & Plano \\
\hline Drenagem & - & Acentuadamente drenado \\
\hline Vegetação primária & - & Floresta Estacional Semidecidual \\
\hline Uso atual & - & Forrageira perene para produção de feno (Tifton 85) \\
\hline \multicolumn{3}{|l|}{ Descrição Morfológica } \\
\hline Ap & - & $\begin{array}{l}\text { 0,00-0,08 m, Bruno-Avermelhado-Escuro ( } 2,5 \mathrm{YR} 3 / 3) \text {; muito argilosa; fraca } \\
\text { pequena e média blocos subangulares e angulares; firme; transição difusa e plana }\end{array}$ \\
\hline $\mathrm{AB}$ & - & $\begin{array}{l}0,08-0,33 \mathrm{~m}, \text { Bruno-Avermelhado-Escuro }(2,5 \mathrm{YR} 3 / 3) \text {; muito argilosa; fraca } \\
\text { grande e média blocos subangulares e angulares; firme a muito firme; } \\
\text { transição difusa e plana }\end{array}$ \\
\hline $\mathrm{BA}$ & - & $\begin{array}{l}\text { 0,33-0,68 m, Bruno-Avermelhado-Escuro }(2,5 \mathrm{YR} 3 / 4) \text {; muito argilosa; fraca } \\
\text { média e grande blocos subangulares que se desfazem em forte pequena e } \\
\text { muito pequena granular; friável a firme; transição difusa e plana }\end{array}$ \\
\hline Bw & - & $\begin{array}{l}0,68^{+} \mathrm{m} \text {, Bruno-Avermelhado-Escuro }(2,5 \mathrm{YR} 3 / 4) \text {; muito argilosa; fraca } \\
\text { média blocos subangulares que se desfazem em forte pequena e muito } \\
\text { pequena granular; friável }\end{array}$ \\
\hline
\end{tabular}


embora tenham sido observadas muitas raízes finas ao longo das camadas iniciais, elas se distribuem horizontal e diagonalmente entre os agregados e raramente dentro dos agregados. Observou-se diminuição das raízes em profundidade, bem como ausência destas nos horizontes BA e Bw. Visualmente, a porosidade interagregados foi a predominante.

A análise morfológica permitiu identificar e localizar as drásticas alterações na estrutura e a presença de camadas compactadas na área cultivada, a exemplo de Tavares Filho (1999) e Ralisch (2002). As modificações dos atributos morfológicos apresentaram-se numa intensidade muito acima da observada em solos similares explorados com agricultura intensiva e mecanizada na região. Os resultados indicam, também, que as alterações devidas ao tráfego de máquinas e implementos, provavelmente em condições de umidade favoráveis à compactação, podem comprometer a estrutura do solo em camadas mais profundas do que as indicadas pelos estudos de Tormena \& Roloff (1996) e Tormena et al. (1998a). Esses resultados são corroborados por Douglas (1994) e Frost (1984), que fazem referência à compactação excessiva do solo em áreas para produção de feno.

As avaliações dos atributos físicos do solo foram utilizadas para quantificar a magnitude das modificações ocorridas nas propriedades e no comportamento físico dos horizontes superficiais e subsuperficiais. De acordo com Assouline et al. (1997), o solo utilizado neste estudo é altamente suscetível à compactação, nas condições de umidade em que são realizadas as operações motomecanizadas durante as atividades de manejo.

Os valores médios da densidade do solo (Ds) são apresentados no quadro 4. ADs apresentou coeficiente de variação similar aos descritos por Imhoff et al. (2001) e Tormena et al. (1998b), e a amplitude de variação da Ds coincide com os valores obtidos por Assouline et al. (1997), em solo similar.
Os valores médios de Ds do horizonte superficial foram significativamente maiores na área sob forrageira em comparação com a área sob floresta, atingindo valores de até $1,60 \mathrm{Mg} \mathrm{m}^{-3}$. Para o horizonte Bw, os valores médios de Ds não diferiram estatisticamente $(p>0,05)$ e foram inferiores a $1,10 \mathrm{Mg} \mathrm{m}^{-3}$, independentemente do sistema de uso. Esses valores caracterizam a Ds de horizontes Bw de Latossolos muito argilosos e indicam que a compactação do solo restringiu-se à camada superficial, como descrito pela análise morfológica do perfil (Quadro 3). A compactação do solo resultou do tráfego de máquinas, possivelmente em condições de solo úmido, como constatado por Cavenage et al. (1999) em áreas de produção de feno. Outros fatores podem contribuir e interagir com o tráfego para aumentar a Ds, como a redução dos teores de matéria orgânica (Silva \& Kay, 1997). Os teores médios de matéria orgânica foram de 47,97 $\mathrm{g} \mathrm{dm}^{-3}$ no solo sob floresta nativa e de $21,41 \mathrm{~g} \mathrm{dm}^{-3}$ no solo sob forrageira, os quais são estatisticamente diferentes $(t=3,75 ; \mathrm{p}>\mathrm{t}=0,0001)$ e estão em acordo com Araújo et al. (2004) e Silva \& Ribeiro (1992).

Os trabalhos de Tormena et al. (1998b) e Klein \& Libardi (2000) indicaram um valor de $\mathrm{Ds}=1,28 \mathrm{Mg} \mathrm{m}^{-3}$ como sendo o valor crítico para crescimento das plantas, em solos de classe textural similar. No horizonte A do solo sob forrageira, todos os valores de Ds foram superiores a $1,28 \mathrm{Mg} \mathrm{m}^{-3}$, caracterizando elevado nível de degradação física do solo. Por outro lado, nos horizontes A e Bw do solo sob floresta e no horizonte Bw do solo sob forrageira, os valores de Ds inferiores a $1,28 \mathrm{Mg} \mathrm{m}^{-3}$ sugerem boa qualidade física e estrutural desses Latossolos.

Outra estratégia adotada para avaliar os resultados de Ds baseou-se na determinação dos valores da Ds em que ocorre ótimo crescimento de raízes $\left(\mathrm{Ds}_{\mathrm{r}}\right)$ e da Ds em que ocorre $20 \%$ do ótimo crescimento radicular $\left(\mathrm{Ds}_{20}\right)$. Essas estimativas foram feitas a partir de

Quadro 4. Momentos estatísticos para a densidade do solo (Ds) avaliada nos horizontes A e Bw do Latossolo Vermelho sob floresta nativa e forrageira

\begin{tabular}{|c|c|c|c|c|c|c|}
\hline & Horizonte & Média ${ }^{(1)}$ & Desvio-padrão & Mínimo & Máximo & CV (\%) \\
\hline \multicolumn{7}{|c|}{ Floresta nativa } \\
\hline \multirow{5}{*}{$\mathrm{Ds}, \mathrm{Mg} \mathrm{m}^{-3}$} & $\mathrm{~A}$ & $1,07 \mathrm{~b}$ & 0,05 & 0,99 & 1,19 & 4,7 \\
\hline & $\mathrm{Bw}$ & $1,07 \mathrm{~b}$ & 0,04 & 0,95 & 1,16 & 2,5 \\
\hline & \multicolumn{6}{|c|}{ Forrageira } \\
\hline & Ap & $1,45 \mathrm{a}$ & 0,06 & 1,35 & 1,60 & 4,1 \\
\hline & $\mathrm{Bw}$ & $1,08 \mathrm{~b}$ & 0,06 & 0,99 & 1,21 & 4,1 \\
\hline
\end{tabular}

\footnotetext{
$\overline{(1)}$ Valores médios seguidos por letras minúsculas diferentes indicam diferenças significativas (teste t) entre os tratamentos no mesmo horizonte $(\mathrm{p}<0,05)$.
} 
funções de pedotransferência obtidas por Jones (1983), em que o teor de silte + argila é a variável independente. Os valores obtidos foram de $1,16 \mathrm{Mg} \mathrm{m}^{-3}\left(\mathrm{Ds}_{\mathrm{r}}\right)$ e $1,42 \mathrm{Mg} \mathrm{m}^{-3}\left(\mathrm{Ds}_{20}\right)$ e confirmam a perda da qualidade estrutural associada ao elevado nível de degradação física do solo cultivado com forrageira para produção de feno, em comparação com o solo sob floresta nativa. As alterações estruturais que resultam da elevação dos valores de Ds predispõem as plantas a estresses físicos por excessiva resistência do solo à penetração e, ou, por reduzida aeração, mesmo quando a disponibilidade de água no solo é adequada.

Os valores médios dos parâmetros descritivos da porosidade do solo para os horizontes A e Bw do Latossolo Vermelho sob floresta e sob forrageira são apresentados na figura 2. Para o horizonte A, observase que os valores de macroporos e de porosidade total foram significativamente menores $(\mathrm{p}<0,05)$ no solo sob forrageira em comparação com o solo sob floresta (Figura 2). A redução da porosidade total pode ser relacionada à redução do volume ocupado por macroporos da floresta $\left(0,14 \mathrm{~m}^{3} \mathrm{~m}^{-3}\right)$ para a forrageira $\left(0,04 \mathrm{~m}^{3} \mathrm{~m}^{-3}\right)$ em função do processo de compactação, como atestam Assouline et al. (1997), Klein \& Libardi (2002) e Araújo et al. (2004). Valores de macroporos inferiores a $5 \%$ também foram constatados por Tormena et al. (1998a) devido ao tráfego de máquinas. A macroporosidade determina a capacidade de aeração do solo, e os resultados indicam que esta é muito baixa no horizonte A do solo sob forrageira (Figura 2). Valores de porosidade com ar abaixo de $10 \%$ são, geralmente, adotados como restritivos para o crescimento e a produtividade da maioria das plantas, apesar da dependência da espécie de planta e da atividade biológica do solo. Nesse solo, o aumento de Ds implica redução da macroporosidade, o que pode induzir uma reduzida difusão de gases no solo em períodos de maior umidade, indicando sérios riscos às plantas. Os baixos valores de macroporosidade ou porosidade com ar também proporcionam elevadas perdas de N por denitrificação (Jensen et al., 1996), e isso pode explicar o amarelecimento de plantas e a necessidade de freqüentes aplicações de fertilizantes orgânicos para manter a produtividade da forrageira nessa área.

Os valores de microporos foram similares entre os tratamentos $(p>0,05)$ nos dois horizontes estudados. Esses resultados são corroborados por Silva \& Kay (1997), os quais indicam que a microporosidade é fortemente influenciada pela textura e pelo conteúdo de $\mathrm{CO}$ e muito pouco influenciada pelos efeitos do manejo. O mesmo comportamento para o volume de microporos também foi comprovado por Machado \& Brum (1978). No horizonte Bw, a ausência de diferenças entre os tratamentos para as variáveis quantificadas sugere que os efeitos do manejo restringiram-se à estrutura do solo das camadas superficiais.

A resistência do solo à penetração $(\mathrm{RP})$ aumenta com a redução da umidade do solo em virtude de

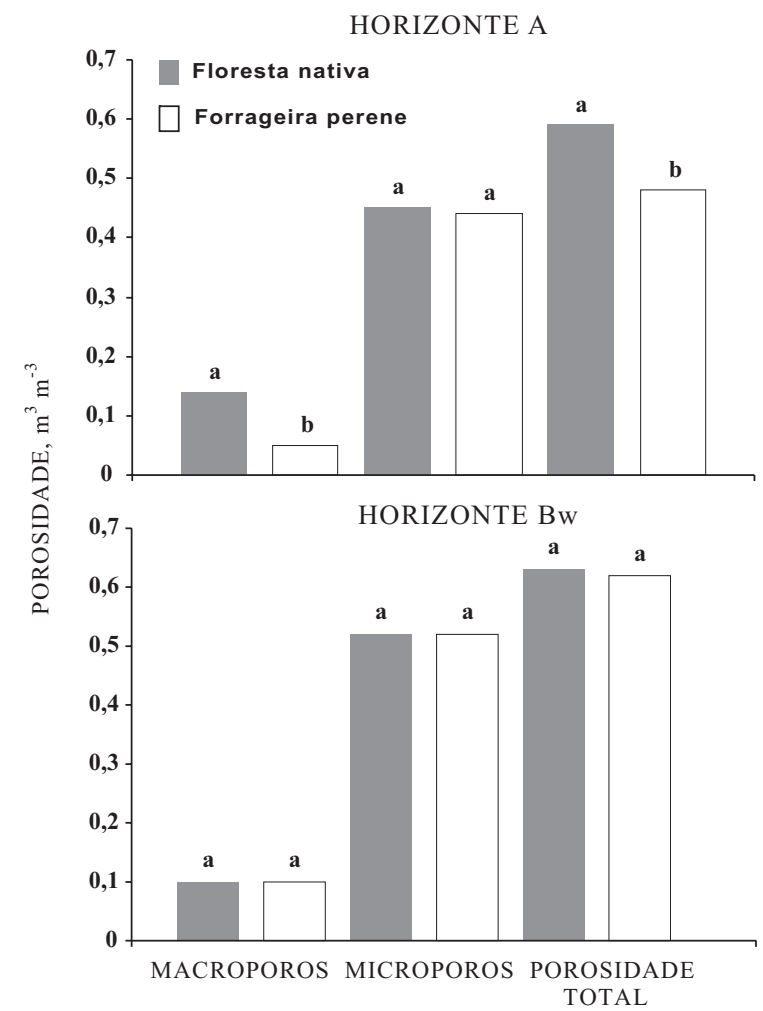

Figura 2. Valores médios de macro, micro e porosidade total dos horizontes $\mathrm{A}$ e $\mathrm{Bw}$ do Latossolo Vermelho sob forrageira e floresta nativa. Para cada parâmetro, valores seguidos por letras minúsculas diferentes indicam diferenças significativas entre os tratamentos $(\mathrm{p}<0,05)$.

aumento no estresse efetivo (Vepraskas, 1984). Por outro lado, o aumento da densidade reduz o volume de macroporos, que, por sua vez, estabelece aumento da $\mathrm{RP}$ e, assim, um impedimento mecânico ao crescimento das raízes, a exemplo do que foi identificado por Cintra \& Mielniczuk (1983). Os resultados do ajuste da equação 1 aos dados de $\mathrm{RP} \mathrm{e}$ do teor de água do solo $(\theta)$, para os horizontes A e Bw dos tratamentos estudados, são apresentados nas equações 2,3 , 4 e 5 .

$\begin{aligned} \text { Floresta Horizonte A: } & \mathrm{RP}=0,1594^{*} \theta^{-2,6793} \\ & \mathrm{R}^{2}=0,71\end{aligned}$

Horizonte Bw: $\mathrm{RP}=0,0879 * \theta^{-3,1135}$

$$
\mathrm{R}^{2}=0,88
$$

Forrageira Horizonte Ap: $\mathrm{RP}=0,8537 * \theta^{-2,4957}$

$$
\mathrm{R}^{2}=0,73
$$

Horizonte Bw： $\mathrm{RP}=0,3023^{*} \theta^{-2,2185}$

$$
\mathrm{R}^{2}=0,89
$$

A RP foi negativamente relacionada com a umidade volumétrica $(\theta)$, corroborando os resultados obtidos por Busscher et al. (1997) e Araújo et al. (2004). Em todos 
os tratamentos, o modelo ajustado explicou acima de $70 \%$ da variabilidade de RP. O comportamento relativo dos parâmetros a e $b$ foi similar entre os sistemas de uso do solo. No entanto, no horizonte A do solo sob forrageira, a magnitude do parâmetro a diferiu substancialmente daquele sob mata. Esses resultados sugerem que o aumento da $\mathrm{RP}$ com o secamento pode estar relacionado ao aumento do estresse efetivo e da densidade do solo, porém com maior contribuição do incremento acentuado da Ds para o horizonte Ap do solo sob forrageira (Quadro 4), resultante do processo de compactação. Essa argumentação é respaldada pelos resultados obtidos por Whaley et al. (2005), os quais indicam que, em solos com elevada densidade, o aumento da RP com o secamento deve-se, em parte, à falta de espaço poroso para deslocamento das partículas durante a medida da resistência, em adição ao efeito estresse efetivo, que aumenta a coesão entre as partículas. Esse fenômeno pode estar também relacionado à presença de argila dispersa no horizonte A do solo cultivado em função da redução dos teores de matéria orgânica (Quadro 4), que também pode contribuir para o aumento da RP com a redução do teor de água do solo.

As equações de 2 a 5 foram utilizadas para estimar a RP considerando a variação de umidade verificada na determinação da $\mathrm{RP}$, e os resultados são apresentados na figura 3 .

Os resultados apresentados na figura 3 indicam que, com o secamento do solo, ocorre incremento acentuado na resistência, com maior intensidade para o horizonte Ap do solo sob forrageira. A compactação do solo afetou profundamente a estrutura do horizonte superficial do solo sob forrageira, o que foi comprovado, neste estudo, pela medida e comportamento da curva de resistência do solo. A resistência do solo à penetração apresenta comportamento similar nos horizontes $\mathrm{A}$ e Bw do solo sob mata e Bw do solo sob forrageira, uma vez que as linhas das curvas não divergem. Por outro lado, no horizonte Bw do solo cultivado, os valores de resistência foram sistematicamente maiores, apesar de os valores de Ds serem similares àqueles do solo sob mata.

No horizonte Ap do solo cultivado, todos os valores de resistência do solo à penetração foram maiores que 2,5 $\mathrm{MPa}$, demonstrando condições altamente impeditivas para desenvolvimento do sistema radicular das plantas mesmo com elevada umidade do solo. No potencial mátrico $(\psi)$ de $-0,01 \mathrm{MPa}$ ou correspondente à capacidade de campo $\left(\theta=0,46 \mathrm{~m}^{3} \mathrm{~m}^{-3}\right)$, os valores médios de RP no horizonte Ap sob forrageira atingem 5,8 $\mathrm{MPa}$, muito acima do valor crítico $(\mathrm{RP}=$ 2,5 $\mathrm{MPa}$ ) para crescimento do sistema radicular de pastagens perenes, conforme indicações de Imhoff et al. (2000). Os resultados indicam que o horizonte Ap do sistema sob forrageira perene não apresenta qualidade física que permita manter elevada produção de biomassa do sistema radicular e da parte aérea da forrageira cultivada na área.
A partir da figura 3 pode-se inferir que o aumento expressivo da resistência no horizonte A do solo cultivado com forrageira perene é determinado pela redução do teor de água e magnificado pela elevada densidade do solo verificada nessa condição (Quadro 4). No horizonte A do solo sob mata e no horizonte Bw dos dois sistemas avaliados, não foram determinados níveis de resistência crítica às plantas numa ampla variação do teor de água do solo (Figura 3), denotando a boa qualidade física do solo nestes horizontes. No entanto, há de se considerar que, mesmo em solo não compactado (solo sob mata e horizonte Bw do solo cultivado), o secamento induz uma elevação substancial da resistência em função dos elevados teores de argila desses solos, o que está em concordância com os resultados obtidos por Smith et al. (1997). Nessas condições de secamento, além da RP, as limitações às plantas também poderão estar associadas à elevada energia de retenção da água no solo.

As alterações dos atributos morfológicos indicaram a degradação física do solo sob pastagem perene, a qual foi confirmada pela quantificação dos atributos físicos. O grau de degradação física superou aqueles verificados em estudos similares em solos da mesma classe textural. Conforme Shierlaw \& Alston (1984), a degradação física do solo pode ser um fator responsável pelos problemas de desenvolvimento e produção da forrageira Tifton 85. Esse grau de deterioração dos atributos físicos não pôde ser visualmente reconhecido no perfil de solo por meio dos atributos morfológicos, que apenas permitiram localizar as modificações decorrentes do cultivo e inferir uma possível degradação da qualidade física do solo. A quantificação de atributos físicos foi essencial para determinar o grau de severidade das alterações ocorridas no sistema de produção de feno e, por sua

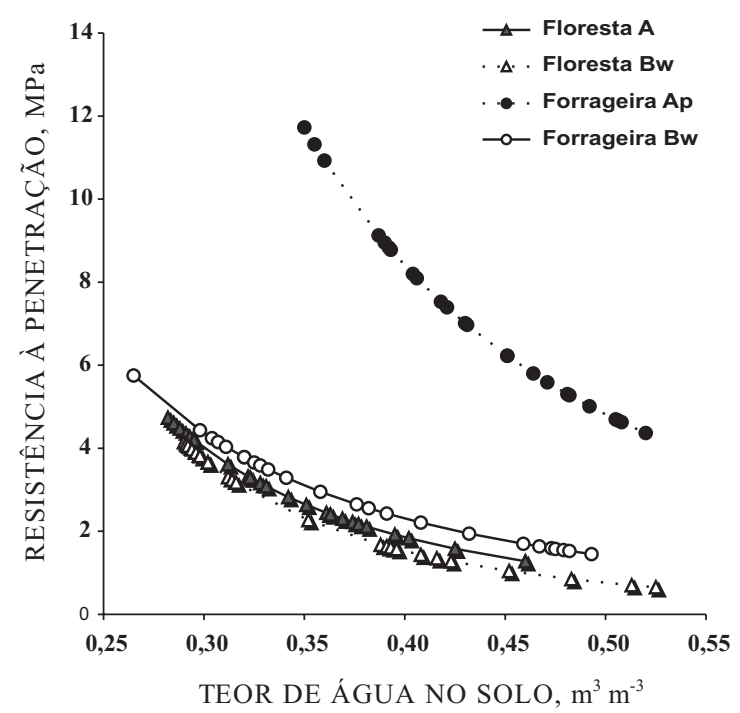

Figura 3. Variação da resistência do solo à penetração em função do teor de água dos horizontes superficial e subsuperficial dos solos sob mata nativa e forrageira perene. 
vez, diagnosticar a perda da qualidade física no solo utilizado para produção de forrageira para feno.

\section{CONCLUSÕES}

1. As alterações ocorridas nos atributos morfológicos e físicos avaliados comprovaram a degradação e a perda de qualidade física do solo utilizado para produção de feno, confirmando a hipótese do trabalho.

2. No solo cultivado com forrageira, verificaramse reduções da macroporosidade e da porosidade total, bem como aumentos da densidade do solo e da resistência do solo à penetração. Sob uso intensivo para produção de forrageira, a camada superficial do solo apresentou volume de poros com ar menor do que $10 \%$ e resistência do solo à penetração superior a $2,5 \mathrm{MPa}$.

3. Os atributos morfológicos apenas permitiram localizar as alterações físicas ocorridas no solo, enquanto as propriedades físicas avaliadas possibilitaram quantificar a ocorrência da degradação física do solo.

4. A curva de resistência do solo refletiu sensivelmente a degradação estrutural da camada superficial do solo cultivado com forrageira para produção de feno.

\section{LITERATURA CITADA}

ARAUJO, M.A.; TORMENA, C.A. \& SILVA, A.P. Propriedades físicas de um Latossolo Vermelho distrófico cultivado e sob mata nativa. R. Bras. Ci. Solo, 28:337-345, 2004.

ASSOULINE, S.; TAVARES FILHO, J. \& TESSIER, D. Effect of compaction on soil physical properties: Experimental results and modeling. Soil Sci. Soc. Am. J., 61:391-398, 1997.

AZENEGASHE, O.A.; ALLEN, V. \& FONTENOT, J. Grazing sheep and cattle together or separately: Effect on soil and plants. Agron. J., 89:380-386, 1997.

BENNIE, A.T.P. Growth and mechanical impedance. In: WAISEL, Y.; ESHEL, A. \& KAFKAFI, U. eds. Plant roots:The Hidden Half. New York, Marcel Dekker, 1991. p.393-414.

BLAKE, G.R. \& HARTGE, K.H. Bulk density. In: KLUTE, A., ed. Methods of soil analysis: Physical and mineralogical methods. 2.ed. Madison, America Society of Agronomy, 1986. p.363-375.

BUSSCHER, W.J.; BAUER, P.J.; CAMP, C.R. \& SOJKA, R.E. Correction of cone index for soil water content differences in a coastal plain soil. Soil Till. Res., 43:205-217, 1997.

CAVENAGE, A.; MORAES, M.L.T.; ALVES, M.C.; CARVALHO, M.A.C.; FREITAS, M.L.M. \& BUZETTI, S. Alterações nas propriedades físicas de um Latossolo Vermelho-Escuro sob diferentes culturas. R. Bras. Ci. Solo, 23:997-1003, 1999.
CINTRA, F.L.D. \& MIELNICZUK, J. Potencial de algumas espécies vegetais para a recuperação de solos com propriedades físicas degradadas. R. Bras. Ci. Solo, 7:197201,1983

DEXTER, A.R. Advances in characterization of soil structure. Soil Till. Res., 11:199-238, 1988.

DOUGLAS, J.T. Responses of perennial forage crops to soil compaction. In: SOANE, B.D. \& van OUWERKERK, C., eds. Soil compaction in crop production. Amsterdam, Elsevier, 1994. p.343-364.

EMPRESA BRASILEIRA DE PESQUISA AGRPECUÁRIA EMBRAPA. Levantamento de reconhecimento dos solos do Estado do Paraná. Curitiba, Embrapa/SNLCS/ SUDESUL/IAPAR, 1984. 791p. (Embrapa-SNLCS, Boletim Técnico, 57)

EMPRESA BRASILEIRA DE PESQUISA AGRPECUÁRIA EMBRAPA. Manual de métodos de análise de solo. 2.ed. Rio de Janeiro, Centro Nacional de Pesquisa de Solos, 1997. 212p. (Embrapa-CNPS, Documentos, 1)

FROST, J.P. Some effects of machinery traffic on grass yield. In: NELSON, J.K. \& DINNIS, E.R., eds. Machinery for silage. British Grassland Soc. Occ. Symp., 17:18-25, 1984.

GIJSMAN, A.J. \& THOMAS, R.J. Evolyution of some physical properties of an oxisol after conversion of native Savana into legume-based on pure grass pastures. Trop. Grasslands, 30:247-248, 1996.

HATCHER, L. \& STEPANSKI, E.J. A step-by-step approach to using the SAS System for Univariate and Multivariate Statistics. Cary, SAS Institute, 1997. 552p.

IMHOFF, S.; SILVA, A.P. \& TORMENA, C.A. Aplicações da curva de resistência no controle da qualidade física de um solo sob pastagem. Pesq. Agropec. Bras., 35:1493-1500, 2000 .

IMHOFF, S.; SILVA, A.P.; DIAS JÚNIOR, M.S. \& TORMENA, C.A. Quantificação de pressões críticas para o crescimento de plantas. R. Bras. Ci. Solo, 25:11-18, 2001.

INSTITUTO AGRONÔMICO DO PARANÁ - IAPAR. Cartas climáticas do Estado do Paraná. Londrina, 2000. CD-ROM

JENSEN, L.S.; MOQUEEN, D.J. \& SHEPHERD, T.G. Effects of soil compaction on N-mineralization and microbial-C and -N. I. Field measurements. Soil Till. Res., 38:175-188, 1996.

JONES, C.A. Effect of soil texture on critical bulk densities for root growth. Soil Sci. Soc. Am. J., 47:1208-1211, 1983.

KERTZMAN, F.F. Modificações na estrutura e no comportamento de um Latossolo Roxo provocadas pela compactação. São Paulo, Universidade de São Paulo, 1996. 132p. (Tese de Doutorado)

KLEIN, V. \& LIBARDI, P.L. Faixa de umidade menos limitantes ao crescimento vegetal e sua relação com a densidade do solo ao longo do perfil de um Latossolo Roxo. Ci. Rural, 30:959-964, 2000.

KLEIN, V.A. \& LIBARDI, P.L. Densidade e distribuição do diâmetro dos poros de um Latossolo Vermelho, sob diferentes sistemas de uso e manejo. R. Bras. Ci. Solo, 26:857-867, 2002. 
KLUTE, A. Water retention: laboratory methods. In: KLUTE, A., ed. Methods of soil analysis: Physical and mineralogical methods. Madison, America Society of Agronomy, 1986 p.635-660.

LEMOS, R.C. \& SANTOS, R.D. Manual de descrição e coleta de solos no campo. 4.ed. Viçosa, MG, Sociedade Brasileira de Ciências do Solo, 2002. 83p.

LETEY, J. Relationship between soil physical properties and crop production. Adv. Soil Sci., 1:277-294, 1985.

MACHADO, J.A. \& BRUM, A.C.R. Efeitos do sistema de cultivo em algumas propriedades físicas do solo. R. Bras. Ci. Solo, 2:81-84, 1978.

MALAVOLTA, E.; LIEM, T.H. \& PRIMAVESI, A.C.P.A. Exigências nutricionais das plantas forrageiras. In: MATTOS, H.B.; WERNER, J.C.; YAMADA, T. \& MALAVOLTA, E., eds. Calagem e adubação de pastagens. Piracicaba, Associação Brasileira para Pesquisa da Potassa e do Fosfato, 1986. p.191-232.

MANICHON, H. Le profil cultural: Une perspective nouvelle pour l'analyse du travail du sol. In: RÉUNION DU GROUPE THÉMATIQUE: STRUCTURE ET FERTILITÉ DES SOLS TROPICAUX, 2., Montpellier, 1995. Anais. Montpellier, ORSTOM, 1995. p.7-14.

RALISCH, R. Compactação de solos. R. Cultivar Máquinas. 5:09-11, 2002.

RALISCH, R.; TAVARES FILHO, J. \& GUIMARÃES, M.F. O perfil cultural na avaliação do manejo e da compactação. In: MORAES, M.H.; MÜLLER, M.M.L. \& FOLONI, J.S.S. Qualidade física do solo. Jaboticabal, Funep, 2001. p.7487.

SAS INSTITUTE. Procedure guide for personal computers. Version 5. Cary, 1999.

SHIERLAW, J. \& ALSTON, A.M. Effect of soil compaction on root growth and uptake of phosphorus. Plant Soil, 77:15$28,1984$.

SILVA, A.P. \& KAY, B.D. Estimating the least limiting water range of soils from properties and management. Soil Sci. Soc. Am. J., 61:877-883, 1997.
SILVA, A.P.; TORMENA, C.A. \& MAZZA, J.A. Manejo físico de solos sob pastagem. In: SIMPÓSIO SOBRE MANEJO DE PASTAGEM, 14, Piracicaba, 1997. Anais. Piracicaba, FEALQ, 1997. p.25-37.

SILVA, M.S.L. \& RIBEIRO, M.R. Influência do cultivo contínuo da cana-de-açúcar em propriedades morfológicas e físicas de solos argilosos de tabuleiro no estado de Alagoas. R. Bras. Ci. Solo, 16:397-402, 1992.

SMITH, C.W.; JOHNSTON, M.A. \& LORENZ, S. The effect of soil compaction and soil physical properties on the mechanical resistance of South African forestry soils. Soil Till. Res., 78:93-111, 1997.

TAVARES FILHO, J.; RALISCH, R.; GUIMARÃES, M.F.; MEDINA, C.C.; BALBINO, L.C. \& NEVES, C.S.V.J. Método do perfil cultural para avaliações do estado físico de solos em condições tropicais. R. Bras. Ci. Solo, 23:393399, 1999.

TORMENA, C.A. \& ROLOFF, G. Dinâmica da resistência à penetração de um solo sob plantio direto. R. Bras. Ci. Solo, 20:333-339, 1996.

TORMENA, C.A.; ROLOFF, G. \& SÁ, J.C.M. Propriedades físicas do solo sob plantio direto influenciado por calagem, preparo inicial e tráfego. R. Bras. Ci. Solo, 22:301-309, 1998a.

TORMENA, C.A.; SILVA, A.P. \& LIBARDI, P.L. Caracterização do intervalo hídrico ótimo de um Latossolo Roxo sob plantio direto. R. Bras. Ci. Solo, 22:573-581, 1998b.

VEPRASKAS, M.J. Cone index of loamy sands as influenced by pore size distribution and effective stress. Soil Sci. Soc. Am. J., 48:1220-1225, 1984.

WARREN, S.D.; NEVILL, M.B.; BLACKBURN, W.H. \& GARZA, N.E. Soil response to trampling under intensive rotation grazing. Soil Sci. Soc. Am. J., 50:1336-1341, 1986.

WHALEY, W.R.; LEEDS-HARRISON, P.B.; CLARK, L.J. \& GOWINGM, D.J.G. Use of effective stress to predict the penetrometer resistance on unsatured soils. Soil Till. Res., 84:18-27, 2005.

WILLATT, S.T. \& PULLAR, D.M. Changes in soil physical properties under grazed pastures. Aust. J. Soil Res., 22:343-348, 1983. 